\title{
EDUCAÇÃO PELAS ÁGUAS: O TERRITÓRIO TRADICIONAL PESQUEIRO COMO ESPAÇO DE EDUCAÇÃO NAO FORMAL
}

\author{
WATER EDUCATION: THE TRADITIONAL FISHERIES \\ TERRITORY AS A FORMAL EDUCATION AREA \\ EDUCACIÓN DEL AGUA: EL TERRITORIO TRADICIONAL DE LA \\ PESCA COMO ÁREA FORMAL DE EDUCACIÓN
}

Marcella Laize da Cruz Gomez ${ }^{1}$

\section{RESUMO}

O texto tem como proposta abordar e analisar o tema da educação não formal frente o contexto e modo de vida dos territórios tradicionais pesqueiros enquanto espaço educativo, discorrendo sobre a leitura e análise das principais referências diante da temática da educação não formal e território tradicional pesqueiro, relacionado-os com o desenvolvimento da participação do sujeito crítico e na defesa do seu território tradicional e nas situações de tomadas de decisões. Esse artigo parte do cenário de reflexões das temáticas citadas, dialogado na perspectiva que as atividades da pesca artesanal na dimensão de seus espaços territoriais também atuam na produção e reprodução do conhecimento.

Palavras-chave: Educação não formal. Espaços não formais. Território Tradicional Pesqueiro. Educação pelas águas.

\begin{abstract}
The text aims to address and analyze the theme of non-formal education in the context and way of life of traditional fishing territories as an educational space, discussing the reading and analysis of the main references on the theme of non-formal education and traditional fishing territory, related to the development of the participation of the critical subject and in the defense of the traditional territory and in the situations of decision making. This article starts from the scenario of reflections of the mentioned themes, dialogued in the perspective that the activities of artisanal fishing in the dimension of their territorial spaces also act in the production and reproduction of knowledge.
\end{abstract}

\footnotetext{
${ }^{1}$ Mestranda do Programa de Pós-graduação em Educação e Contemporaneidade- Universidade do Estado da Bahia - UNEB. Membro do Grupo de Pesquisa Teoria Social e Projeto Político Pedagógico - TSPPP. Graduada em Licenciatura em Ciências Biológicas. E-mail: cellagomez@ hotmail.com
} 
Key words: Non formal education. Non formal spaces. Traditional Fishing Territory. Watereducation.

\section{RESUMEN}

El texto tiene como objetivo abordar y analizar el tema de la educación no formal en el contexto y en la forma de vida de los territorios pesqueros tradicionales como un espacio educativo, discutiendo la lectura y el análisis de las principales referencias sobre el tema de la educación no formal y el territorio pesquero tradicional, relacionado con el desarrollo de la participación del sujeto crítico y en la defensa de su territorio tradicional y en las situaciones de toma de decisiones. Este artículo parte del escenario de reflexiones de los temas mencionados, dialogados en la perspectiva de que las actividades de pesca artesanal en la dimensión de sus espacios territoriales también actúan en la producción y reproducción del conocimiento.

Palabras clave: Educación no formal. Espacios no formales. Territorio Pesquero Tradicional. Educación por el agua.

\section{INTRODUÇÃO}

"Jogou sua rede, ó pescador": pescando conhecimento nas águas do saber

Uma sociedade democrática só é possível pelo caminho da participação social, é o que defende Gohn (2001), que em suporte com o conceito de comunidade educativa, aborda que os territórios empíricos e suas relações atuam como espaço de articulação diante da presença dos sujeitos nos diversos processos educacionais.

A leitura do conceito comunidade educativa possibilita expandir a compreensão que a educação não é definida exclusivamente pelos métodos e abordagens do ensinoaprendizagem do sistema formal de ensino. Onde, as situações geradas no cotidiano diante dos processos interativos dos sujeitos com o ambiente e sua relação com os fenômenos no dia-a-dia fomentam embasamentos para resoluções dos problemas de sobrevivência, formando elementos do campo da educação não formal (GOHN, 2001).

Quanto à noção de educação não formal, Gadotti (2005) define que essa modalidade de educação não deve ser compreendida apenas como oposição, ou até mesmo negação à educação formal, mas sim pela sua essência, sendo essa mais difusa e sem as burocracias do sistema regular de ensino. Em Gohn (2005), a mesma aborda que a educação não formal 
ultrapassa as barreiras do ensino formal e considera as experiências de vida, sobretudo nos espaços de ações coletivas do cotidiano como terreno dos processos de aprendizagem.

Tomando como referência os conceitos sobre educação não formal e dos espaços não formais na elaboração e articulação de práticas educativas, bem como o desenvolvimento de processos de aprendizagens construídos por relações sociais, coletivas e participativas para as tomadas de decisões populares nos territórios inseridos, esse artigo parte do cenário de reflexões desses conceitos citados e dialogados frente as autorias apresentadas, na perspectiva que as atividades da pesca artesanal na dimensão de seus espaços territoriais também atuam na produção e reprodução do conhecimento.

Como parte dessa análise, a exemplo da sabedoria dos povos das comunidades tradicionais pesqueiras diante das dinâmicas das marés, do comportamento dos recursos pesqueiros, do trabalho da mariscagem, o beneficiamento do pescado, a elaboração de apetrechos, comercialização e afins.

Sob essa perspectiva, esses conhecimentos construídos e transmitidos se somam no movimento de fortalecimento de processos identitários, na leitura do mundo frente a relação com o ambiente e na elaboração de elementos e estratégias de gestão e defesa do território tradicional pesqueiro pela participação popular. Ou seja, uma educação pelas águas.

Assim, compreensão de uma educação pelas águas parte como referência de um movimento de aprendizado não formal diante das marés, do território pesqueiro enquanto um território orgânico que educa os sujeitos tradicionais ali pertencentes, que nesse convívio com o espaço e juntamente com as pessoas que se relacionam nele, fomentam aspectos sobre o pertencimento, defesa e conservação do local.

\section{EDUCAÇÃO NÃO FORMAL: breves conceitos}

Segundo Gadotti (2005) a educação não formal é uma atividade educacional organizada e que também apresenta uma sistemática, porém com determinadas especificidades e desenvolvida no espaço fora do sistema formal de ensino. $\mathrm{O}$ autor ainda chama atenção para dois aspectos marcantes na educação não formal: espaço e tempo, sendo"uma das características da educação não-formal é sua flexibilidade tanto em relação 
ao tempo quanto em relação à criação e recriação dos seus múltiplos espaço" (GADOTTI, 2005, p. 3).

Em Souza (2008) a educação não formal é definida por se relacionar com as questões de aprendizados diferentes do contexto escolar e com a valorização das relações sociais por meio da práxis, sendo comumente desenvolvida por movimentos sociais, organizações populares e o organizações não governamentais.

Na perspectiva de Gohn (2014) a educação não formal reúne ideias e saberes produzidos, herdados e novos adquiridos, que são socializados diante das experiências, onde o conhecimento trata-se de um processo histórico e sociocultural que ocorre por modos próprios e pertencente de cada cultura. De tal forma que "a educação não formal é aquela que se aprende "no mundo da vida", via os processos de compartilhamento de experiências, principalmente em espaços e ações coletivos cotidianas" (GOHN, 2014, p. 40).

Em diálogo com essa leitura que os diversos espaços são formadores e educativos, esse textose apóia também no pensamento que Paulo Freire (1989) traz sobre o papel preponderante da educação nos processos de transformação das condições sociais frente à participação popular, considerandoos contextos históricos e socioculturais nos quais se inserem o existir. Na sua concepção de práxis pedagógica, o autor já dialogava essa participação social na elaboração da ideia de uma cidadania popular, e afirma que "a cidadania se cria com uma presença ativa, crítica decidida, de todos nós com relação à coisa pública" (FREIRE, 1995, p.74).

Assim, seguindo por esse pensamento da importância da educação, abordada no texto enquanto educação não formal, uma estreita relação é apontada na formação do sujeito crítico e participativo na garantia da cidadania como um direito, como aborda Maria Gloria Gohn:

\footnotetext{
É no plano local, especialmente num dado território, que se concentram as energias e forças sociais da comunidade, constituindo o poder local daquela região; no local onde ocorrem as experiências, ele é a fonte do verdadeiro capital social, aquele que nasce e se alimenta da solidariedade como valor humano.(GOHN, 2004, p. 49).
}

Contudo, Gohn (2004) reconhece os desafios da articulação dos elementos, espaços e sujeitos e inseridos no território e na construção do sentido mais amplo desse processo de formação dos indivíduos como cidadão se como se configura como uma demanda da sociedade atual, propondo a participação e articulação com toda da sociedade civil organizada.

Revista Educação e Ciências Sociais (ISSN: 2595-9980), Salvador, v.2, n.3, 2019 
Nesse texto o conceito de educação não formal articula-se também com as ideias de educação cidadã, com a educação não formal atuando na formação de cidadãs (aos) emancipadas (os), por meio de um processo cultural e pedagógico (GOHN, 2014).

Vale destacar, que essa relação da educação não formal, cidadania e também participação popular se baseia na perspectiva de uma cidadania coletiva, com os sujeitos atuando diante de interesses entre seus pares. Gohn (2012) retrata por meio do resgate histórico as mudanças da concepção do conceito de cidadania ao longo do tempo, e ao situar o século XX descreve como o projeto de Estado burguês desenvolveu uma ênfase por uma cidadania cívica, voltada, sobretudo para os deveres dos cidadãos e fortalecimento da regulação pelo Estado. Ainda no mesmo período, com o crescimento do neoliberalismo no Brasil, houve um movimento de educar sujeitos a serem civilizados para uma sociedade urbanizada, como forma de superar as realidades do espaço do campo, por meio de uma perspectiva estigmatizada desse território, lido então como não desenvolvido, formando assim cidadãs (ões) para a vivência com o dito moderno, nesse caso o urbano.

Todavia, outro conceito de cidadania em oposição ao modelo capitalista e explorador da condição humana parte dos movimentos sociais e grupos organizados, com a noção de uma cidadania coletiva forjada pelos interesses comuns das classes e grupos da sociedade organizada como forma de superar as desigualdades e em defesa dos direitos sociais (GOHN,2012).

Nesse sentido, a educação não formal diante do desenvolvimento de práticas educativas voltadas para a construção dessa cidadania coletiva e lutas por direitos e faz como instrumento essencial para a participação social na coletividade frente às questões sociais por meio de uma prática emancipatória (GOHN, 2011), uma vez que "a educação ocupa um lugar central na acepção coletiva da cidadania. Isto porque ela se constrói no processo de luta que é, em si próprio, um movimento educativo" (GOHN, 2012, p.21).

Para Morin (2000, p. 74) “a verdadeira transformação só poderia ocorrer com a inter transformação de todos, operando assim uma transformação global, que retroagiria sobre as transformações individuais".

No que tange a ideia do saber popular, Boaventura de Sousa Santos (2007) no seu conceito de "ecologias de saberes", analisa justamente o diálogo entre diferentes formas de saberes e conhecimentos existentes na sociedade, onde no campo dessa pluralidade se faz necessário a inserção e a maior participação dos grupos sociais na garantia de seu protagonismo de elaboração das práticas emancipatórias (SANTOS, 2007). Reforçando 
assim que a educação é um processo de interação que ocorre o tempo todo (MATURAMA, 1999).

\section{TERRITÓRIO TRADICIONAL PESQUEIRO: o movimento das águas como espaço de saber}

\section{“(...) Papai era pescador, mamãe lavadeira, eu ganhava meus trocados vendendo beiju na} feira...” Trecho da música Lição de vida

A atividade pesqueira no Brasil, em especial no que se refere à pesca artesanal é desenvolvida como forma de garantir a sobrevivência e reprodução social das comunidades tradicionais pesqueiras distribuídas pelo país (DIEGUES,1983).

No que se refere ao modo de vida, segundo Alves (2015) ser pescador(a) artesanal configura-se como uma resistência, pois inúmeras comunidade encontra-se em um processo de transição diante do contexto rural-urbano, fazendo com que esse modelo de produção, consumo, bem como as relações sociais, interferiam na produção do espaço da comunidade, gerando um impacto na reorganização das práticas sociais.

Em Rios (2012) para essas comunidades pesqueiras, a pesca artesanal é compreendida como uma profissão e modo de vida, reforçado com o domínio de técnicas e conhecimentos que embasam a habilidade e a garantia da subsistência.

Nos escritos de Diegues (1983) sobre a vivência desse modo de existir, o autor declara "que caracteriza o pescador artesanal não é somente o viver da pesca, mas é sobretudo a apropriação real dos meios de produção; o controle de como pescar e o que pescar, em suma o controle da arte da pesca" (DIEGUES, 1983, p.198).

Nessa compreensão da relação dos sujeitos e o território de existência, compreendese também os pescadores artesanais enquanto grupo social de comunidades tradicionais que tem sua vivência diretamente do meio natural, e desenvolvem suas próprias formas de manejo dos recursos da natureza, sobretudo de modelo mais sustentáveis do que o modo industrial de produção pesqueira, e com isso devem ser considerados como agentes que contribuem com a conservação desses território. (ALVES, T. et al., 2013).

Para o Movimento de Pescadores e Pescadoras Artesanais -MPP/BA (2015) a relação de apropriação desenvolvida pelos pescadores artesanais com a natureza é caracterizada pelos laços de identidade e pertencimento com os elementos das águas e da Revista Educação e Ciências Sociais (ISSN: 2595-9980), Salvador, v.2, n.3, 2019 
terra. Onde, os valores simbólicos e materiais asseguram o seu modo de vida tradicional (RIOS, 2012).

Desse modo, Alves (2015) e Rios (2012) afirmam que é no desenvolvimento dessas relações que as comunidades tradicionais pesqueiras vem construindo e delimitando seus territórios como espaços utilizados e para o desenvolvimento de suas atividades produtivas e sociais, e por vez, repletos de valores materiais e imateriais. Ou seja, o seu território social.

Outro elemento fundamental, que é abordado por Little (2002), sobre territórios sociais, é que nesses espaços são encontrados vínculos sociais, simbólicos e rituais, com a manutenção de seus respectivos ambientes biofísicos, o que explica a relação que grupos socais mantém com seus territórios diante de seus saberes, suas ideologias e identidades, coletivamente criados e historicamente situados na manutenção e socialização desses espaços específicos.

Machado (2007) discute que no caso das comunidades pesqueiras, o ambiente em usufruto compreende seu território, pois se trata do uso específico desse espaço pela comunidade tradicional, havendo uma relação dialética entre os sujeitos e o meio natural que os cercam, em que suas dinâmicas com os territórios modificam a paisagem de acordo com o contexto vivido.

Tratando-se do cenário baiano, embora pouco divulgada, a produção pesqueira no estado da Bahia ocupa a terceira colocação em relação ao país, sendo a primeira da região nordeste (BAHIA PESCA, 2003). O litoral da Bahia possui atualmente cerca de 350 comunidades pesqueiras identificadas, distribuídas em 44 municípios (SOARES et al, 2009).

Contudo, mesmo ressaltando a sua importância socioeconômica, ecológica e cultural para a sociedade, Alves (2015) e Rios (2012), analisam que nas últimas décadas são constantes as denúncias feitas pelas (os) pescadoras (os) sobre os impactos no seus territórios, a exemplo de poluição das águas, ocupação e desmatamento do manguezal, especulação imobiliária, complexos industriais, entre outros. Desta forma os territórios pesqueiros têm sido modificados em decorrência dos grandes impactos (MPP, 2015).

Partindo da referência do território tradicional pesqueiro ameaçado, com a inserção de empreendimentos industriais, por exemplo, e somados com a invisibilidade histórica, quem em certa medida, silencia as evidências e contradições existentes e influenciados no surgimento das inúmeras disputas territoriais e conflitos, como abordado em Rios (2015); sendo esses elementos um das principais causas das disputas territoriais que envolvem as comunidades tradicionais pesqueiras no litoral do Estado da Bahia (PAIVA, 2011). Essa 
realidade por sua vez vem exigindo as estratégias dos movimentos de sociais e organizações de base na formação de fortalecimento da identidade para e incidir sobre a dinâmica do local, inclusive nos setores do Estado, como nas políticas públicas. (MPP, 2015).

Monteiro (2014) reforça esse aspecto dos conflitos inseridos nos territórios pesqueiros e faz uma análise sobre o modelo pautado de crescimento do estado brasileiro voltado expressivamente em interesses econômicos e muitas vezes alinhado com as iniciativas do capital privado, se revelando como uma oposição ao uso do território tradicional pelas comunidades tradicionais pesqueiras, onde se tratando de contaminação, cita a conjuntura que retrata a Área de Proteção Ambiental Baía de Todos os Santos - APA BTS, localizada no Estado da Bahia, que apresenta altos índices de poluição química resultante das atividades industriais do setor petroquímico, apontando que tal cenário ameaça a produção e modo de vida das comunidades pesqueiras. Todavia, em resposta a esse panorama de violação do bem viver das comunidades tradicionais pesqueiras, o que se acompanha é o fato que pescadoras (res) artesanais se organizam politicamente frente ao direitos pelo seu território tradicional pesqueiro.

\section{FENÔMENO DAS RESSURGÊNCIAS: alguns aspectos de resistência popular}

No campo das ciências que estudam elementos oceanográficos, a ressurgência é definida de forma geral como o deslocamento de águas subsuperficiais. Ou seja, as mais profundas e abundantes em nutrientes se direcionam para as camadas superficiais do oceano; nesse instante, passa a existir um afloramento que resulta em altos níveis de produtividade primária e produção pesqueira. Uma verdadeira explosão, digamos. Não irei aqui tratar sobre aspectos biológicos desse fenômeno, mas cito para fazer uma analogia às ressurgências da participação popular que atuam nos processos e cenários de conflitos, onde uma vez articuladas com a aprendizagem nos processos não formais, se expressam no fortalecimento e aprofundamento dos sujeitos como leitura crítica à realidade; sobretudo mediante a movimentação da participação popular em espaços de tomadas de decisões (exemplo conselhos, grupos gestores), e auto organizados, como colônias, associações, grupos comunitários e demais, atuando de forma conforme seus princípios, bandeiras de luta e projeto de sociedade.

Revista Educação e Ciências Sociais (ISSN: 2595-9980), Salvador, v.2, n.3, 2019 
Ao longo da história, (as) os pescadoras (es) artesanais acumulam experiências de lutas e resistências. Em sua obra que retrata sobre os pescadores na história do Brasil, Silva (1988) considera que os primeiros indícios de luta das (os) pescadores (as) registra-se durante o processo marcante da abolição da escravatura, onde durante o período imperialescravista (1822-1889), não se nota mudanças de fato na realidade dos pescadores artesanais. Em registro:

Como qualquer outra classe oprimida, os pescadores não tiveram nenhuma melhoria mais significativa após a emancipação política, pois permaneceram em níveis de vida tão ínfimos quanto nos períodos coloniais. Não se pode esquecer que algumas mudanças ocorreram para os pescadores do século XIX: diversificaram-se as formas de atividades complementares à pesca, aumentou o número de povoados litorâneos formados, sobretudo por pescadores, bem como aumentou o próprio número destes últimos. Por outro lado, novas formas de controle foram impostas à produção e à comercialização do pescado, e novos e abusivos impostos foram lançados a estas mesmas atividades, através das câmaras municipais e do Ministério da Agricultura, Comércio e Obras Públicas do Império. Ao mesmo tempo, atestando a importância da pesca e dos pescadores, tentou-se no segundo reinado, pela primeira vez, regulamentar todos os pescadores brasileiros, além de dividi-los em distritos. (SILVA, 1988, p. 98).

Já no período da República Velha (1889-1930), um marco no modelo de organização da pesca artesanal no Brasil se faz pela criação das primeiras Colônias de Pescadores, no ano 1919. Silva (2004) explica que a criação das colônias de pesca se fizeram por interesses do Estado brasileiro, tanto como forma de garantia do contingente de pescadores como reserva pela Marinha do Brasil, como também em respostas aos interesses de abastecimento e controle do mercado pela a expansão da industrialização da pesca artesanal. Contudo, em 1973 as Colônias passaram a serem organização de classe pesqueira artesanal, e no ano 1988, na Constituição Federal, as Colônias enfim são equiparadas aos sindicatos, formando um processo de livre associação da classe pesqueira (SILVA, 2004).

Hugo Caetano (2013), em sua pesquisa sobre o conhecimento e aprendizagem das experiências das pescadoras marisqueiras do município de Salinas da Margarida-BA, firma que é notório na atividade da pesca a presença de redes de solidariedades, a exemplo da partilha de alimentos, as trocas de informações e ideias sobre os costeiros mais produtivos e etc. que se expressam na base deste ambiente de convivência e atividade pesqueira a realização do ensino e a aprendizagem (CAETANO, 2013). 
Caetano (2013) ainda aborda a questão do crescimento da organização das comunidades tradicionais pesqueiras, que conta com a emergência dos movimentos sociais da classe pesqueira no Brasil e vem ganhando repercussão e inserção a nível nacional.

Nesse aspecto, Alves discute que os debates da garantia dos direitos e ao território protegido se fortaleceram na classe pesqueira artesanal pela consciência política, que passou a ser reforçada sobre seus espaços de produção, visto as ameaças pelos modelos de desenvolvimento posto. Assim, esse movimento revela o campo das forças em que se constitui a atividade da pesca artesanal no país, que parte em defesa pelo seu espaço de reprodução social.

Esse movimento de defesa e reivindicação é histórico e permeia de dinâmica dos povos e comunidades tradicionais, como afirma Little (2002), “[...] Os territórios dos povos tradicionais fundamentam-se em décadas, em alguns casos, séculos de ocupação efetiva. A longa duração dessas ocupações fornece um peso histórico às suas reivindicações territoriais [...]"( LITTLE, 2002, p.265).

Paulo Freire (1980) aborda que é por meio da permanente ação transformadora da liberdade objetiva, que os sujeitos criam a história e se fazem seres histórico-sociais. Onde, a libertação dos oprimidos é a libertação das pessoas e não de 'coisas'. O que o mesmo chama de auto-libertação. Partindo desse pensamento freireano, vale reforçar que ninguém se liberta sozinho, como também não há uma libertação de uns feito por outros, mas sim homens e mulheres se libertando em simultaneidade. E como isso se expressa nos territórios tradicionais pesqueiros? Podemos observar alguns desses aspectos na organicidade da atuação comunitária, com a elaboração de agendas formativas, na mobilização de bases e lideranças, que no seu território social constroem seus elementos educadores em diálogo com as características do ambiente produtor e reprodutor do conhecimento. Como citado em Milton Santos (2006), que a existência é produtora de sua própria pedagogia.Dessa forma, compreendendo o papel da educação, que inclusive citada pela LDB n 9.394/96 (Lei de Diretrizes e Bases da Educação), expressa já em seu artigo $1^{\circ}$, como um conceito que não se restringe apenas ao ensino escolar regular, mas tem por dever abrigar e abranger os processos formativos que se desenvolvam na convivência humana, nos movimentos sociais e organizações da sociedade civil e nas manifestações culturais, por exemplo.

Assumindo a concepção da educação como multidimensionalidade da condição humana, que interage com dinamismo social, em reforço essa definição com as ideias Humberto Maturana (1999) que a educação é esse processo de interação ininterrupto com convívio em sociedade. 
Corroborando com essa concepção, Gonh (2001) descreve que as abordagens educacionais tem por direito dialogar com o fortalecimento do território frente ao papel fundamental na defesa do espaço social.

\section{CONCLUSÃO}

A educação e suas relações com a sociedade estão em constante movimento e por sua vez repensadas, desconstruindo o pensamento que os processos de aprendizagens ocorrem apenas pelo modelo convencional da educação formal.

Compreende-se assim a potencialidade dos espaços não formais, as situações do cotidiano e processos interativos do indivíduo com o ambiente como de caráter formador no desenvolvimento da participação popular em espaços de tomadas de decisões, bem como na elaboração de estratégias de autogestão e defesa do território tradicional pesqueiro.

Por fim, é nessa linha de reflexões e discussões sobre a educação não formal e sua práxis tomando como recorte a perspectiva do território tradicional pesqueiro como espaço próprio de formação e fortalecimento identitário da comunidade tradicional da pesca artesanal, entende-se então que essa educação se expressa nesse aspecto de saber para além de processos de escolarização e normatizações burocrática, estando relacionada com o comportamento das (os) pescadoras (res) em sua práticas de cotidiano, da historia com o local, da leitura da realidade, nas ações coletivas organizadas e sistematizadas por meio de movimentos populares da classe da pesca artesanal, entre outros. Uma educação pelas águas, construída e remada pelos povos das marés.

\section{REFERÊNCIAS}

ALVES, T. A pesca artesanal em Baiacu - Vera Cruz (BA): identidades, contradições e produção do espaço.2015.149f. Dissertação (Mestrado em Geografia) - Universidade Federal da Bahia. Salvador (Ba), 2015.

ALVES, T. et al. Pesca artesanal, territórios pesqueiros e conflitualidades. Salvador: 2013.

BAHIA PESCA. Boletim estatístico da pesca marítima e estuarina. Salvador: Bahia Pesca, 2003.

Revista Educação e Ciências Sociais (ISSN: 2595-9980), Salvador, v.2, n.3, 2019 
BRASIL. LDB: Lei de diretrizes e bases da educação nacional.2. ed. Brasília: Senado Federal, Coordenações de Edições Técnicas, 2018.

CAETANO, Hugo Silva. Na Maré e na Escola: Experiências educativas de marisqueiras em Salinas da Margarida. 2013. Dissertação (Mestrado em Educação e Contemporaneidade) - Universidade do Estado da Bahia, 2013.

DIEGUES, A. C. Pescadores, camponeses e trabalhadores do mar. São Paulo:Ática, 1983.

FREIRE, Paulo. Pedagogia do oprimido. Rio de Janeiro: Paz e Terra, 1980.

FREIRE, Paulo.Que fazer: teoria e prática em educação popular. 2. ed.

Petrópolis:Vozes, 1989.

FREIRE, Paulo. In: Fórum de Participação Popular das Administrações Municipais: Poder local, participação popular e construção da cidadania. Belo Horizonte: Instituto Pólis, 1995.

GADOTTI, Moacir. A questão da educação formal/não-formal. Institutinternational des droits de l'enfant (IDE) Droit à l'éducation: solution à touslesproblèmes ou problèmes nas solution? Sion (Suisse), 18 au 22 octobre. 2005. p.1-11.

GOHN, Maria da Glória. A educação não formal e a relação da escola-comunidade. Eccos Revista Científica, São Paulo, v. 6, n. 2, p. 39-65, dez. 2004.

GOHN, Maria da Glória. Educação não formal, aprendizagens e saberes em processos participativos. Investigar em Educação, série 2, n. 1, p.35-50, nov.2014.

GOHN, Maria da Glória. Educação não-formal e cultura política. 2. ed. São Paulo: Cortez, 2001.

GOHN, Maria da Glória. Educação não-formal e cultura política: impactos sobre o associativismo do terceiro setor. 2.ed. São Paulo, Cortez, 2005.

GOHN, Maria da Glória.Movimentos sociais e educação. 8. ed. São Paulo: Cortez,2012.

LITTLE, Paul E. Territórios sociais e povos tradicionais no Brasil: Por uma antropologia da territorialidade. Série Antropologia n. 322. Brasília, UnB: 2002.

MACHADO, Denise. Catadoras de caranguejo e saberes tradicionais na conservação de manguezais da Amazônia brasileira. Estudos Feministas, Florianopolis, v. 2, n. 15, p.240$240,2007$.

MATURANA, H. Emoções e linguagens na educação e na política. Belo Horizonte: UGMG, 1999.

MONTEIRO, Igor Ramos T. Modelagem etnoecológica do território da pesca artesanal em Ilha de Maré, Salvador-BA. 2014. 100f. Dissertação (Mestrado em Ciências Ambientais) - Universidade Estadual de Feira de Santana, Feira de Santana, 2014. 
MORIN, Edgar. Os sete saberes necessários à educação do futuro. Tradução de Catarina Eleonora F. da Silva e Jeanne Sawaya. Revisão técnica de Edgar de Assis Carvalho. 2. ed. rev. São Paulo: Cortez; Brasília, DF: UNESCO, 2000.

MPP. Movimento dos Pescadores Artesanais. Cartilha Movimento Pescadores e Pescadoras Artesanais. Bahia, jul. 2015.

PAIVA, Ayane de Souza et. al.Aspectos socioambientais ligados ao mar e aos manguezais da Ilha de Maré. In: ALMEIDA, Rosiléia Oliveira de; NEVES, Ednaldo Luz das (Org.). Caderno Ambiental de Ilha de Maré. Salvador: Unijorge, 2011.

RIOS, K. A. N. Da produção do espaço a construção dos territórios pesqueiros: pescadores artesanais e carcinicultores no distrito de Acupe - Santo Amaro (BA). 2012. 263f. Dissertação (Mestrado em Geografia) - Universidade Federal da Bahia, 2012.

SANTOS, Boaventura de Sousa.Para além do pensamento abissal: das linhas globais a uma ecologia de saberes. In: Novos estud. - CEBRAP [online]. 2007, n.79, pp.71-94. ISSN 0101-3300. Disponível em:http://dx.doi.org/10.1590/S0101-33002007000300004.Acesso em: 21 dez. 2019.

SANTOS, M. Por uma outra globalização: Do pensamento único à consciência universal. Rio de Janeiro: Record, 2006.

SILVA, Luiz Geraldo. Caiçaras e jangadeiros: cultura marítima e modernização no Brasil (1920-1980). São Paulo-SP: Série e Documentos Relatórios de Pesquisa, n. 1. 2004.87p.

SILVA, Luiz Geraldo. Os pescadores na história do Brasil, v. 1. Colônia e Império. Comissão Pastoral do Pescador. Luis Geraldo Silva (coordenador). Recife-PE, 1988.

SOARES, Lucy Satiko Hashimotoet al. Pesca e Produção Pesqueira. In: Baía de Todos os Santos: aspectos oceanográficos. Salvador: EDUFBA, 2009.

SOUZA, Cléia Renata Teixeirade. A educação não-formal e a escola aberta. Paraná: EDUCERE, 2008. 